\title{
نموذج مقترح لتنمية المهارات القيادية لاى معلمى التربية الرياضية بمحافظة أسوان في ضوء القيادة الإستيراتيجية
}

/ / محمد حسن حفنى

\section{المقدمة و مشكلة البحث}

تقاس مؤشرات حضارة الأمم وارتقائها في مدى عنايتها بتربية الأجيال بمختلف

فئاتها، وتوفير إمكانات النمو الثنامل من كافة الجوانب مما يساعد في إعدادهم لحياة شخصية واجتماعية ونفسية ناجحة يؤدى فيها كل منهم دوره في خدمة المجتمع مهما كان حجم إسـهامه، أمـا إهمـال هذه الفئة فيؤدى إلى تفـاقم مشكلاتهم وتضـاعفها،

$$
\text { ويصبحون بالتالي عالة على أسرهم ومجتمعهم. (9 : 0 1 ) }
$$

وتعد القيادة من أهم العمليات نأثيراً على السلوك ، فهى تؤثز تأثيراً كبيراً فى

دافعية الأفراد ، وفى اتجاهاتهم ورضائهم عن العمل ، وهى محور رئيسى للعلاقة بين

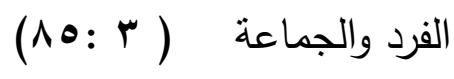

معلم خبير تربية رياضية عضو مجلس إدارة فرع أسوان لكرة السلة . سكرثير لجنة حكام تنس الطاولة ـ سكرتير لجنة حكام الكرة الطائرة ـ المدير الإدارى لحمام السباحة 
وتثير " سوسن عبد الفتاح " (990 ) إلى أن القيادة ترتبط بالفرد في إطار الجماعة والمواقف والأهداف المراد تحقيقها ، فإذا اختلفت فان هذا يتطلب اختلاف في أساليب القيادة واختلاف الجماعات له تأثثر فى أسلوب القيادة وفاعلية القائد فى تحقيق أهداف العمل ورضا أفراد الجماعة ينوقف على ندط القيادة المتبع أو أنماط السلوك القيادي الذى يمارسه في علاقته بأفراد جماعته والسلوك القيادي هو سلوك القائد تجاه جميع أفراد الموقف وهو محصلة التفاعل الذي يحدث بين جميع مكونات

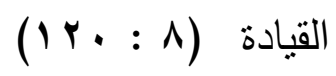

وللقيادة دور كبير فى بناء الجماعات المختلفة فالقائد يلعب دور بالغ الأهمية

في تماسك الجماعة وقد لا يستخدم القائد أسلوباً واحداً لا يحيد عنه بل قد يكون للقائد عدة أساليب ، ومع ذلك لابد أن يكون هنآك أسلوب يظلب على سلوكه معظم الوقت وهو الذى يتحدد على أساسه نمطه القيادي وهناك ثلاثة عوامل أساسية فى كل موقف قيادي تتفاعل مع بعضها البعض، لكى تحدد النمط القيادي التلازم تطبيقه وهى : الأبعاد الثخصية والقدرات والمهارات وقيم واتجاهات القائد والتابعين فى ضوء احتياجاتهم ودوافعهم واتجاهاتهم ومثاعرهم وقدراتهم والتى تحدد السلوك القيادى الذى يستجييون له بفاعلية 
والظـروف المحيطـة بـالموقف من ناحيـة طبيعـة المشكلة القائمـة وظروفها وأبعادهـا

$$
\begin{aligned}
& (Y): V) \\
& \text { ومدى الوقت المتاح لاتخـاذ القرار }
\end{aligned}
$$

كما يضم المجال الرياضى العديد من الأنشطة المختلفة فى قطاعات متعددة وتبعاً لذلك تتعدد المواقف السلوكية للجماعات من حيث الحدة والنوع ومن خلال هذه المواقف نجد أن لكل قائد أسـلوبه الخـاص فى توجيـه مرعوسيه أسـاس القيادة هـو اشتراك القائد والتابعين فى تحقيق أهداف مشتركة والقائد ليس الثخص الذى يتحلى

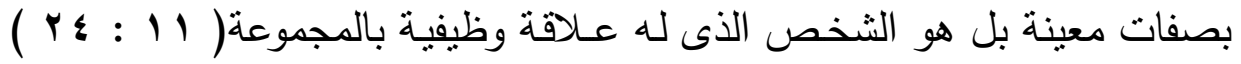
وللقيادة تأثنيرها القوى المباشر على كفاءة أبي منظمـة من المنظمات فى القيام بمسئولياتها وتحقيق أهدافها فتقوم على التفاعل بين القائد وأفراد جماعته تبعاً للنمط

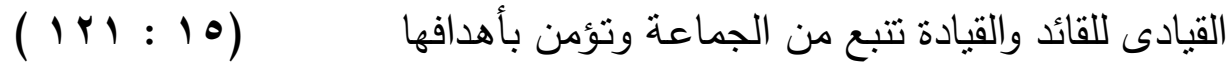
وتوجـه المجتمعـات اهتمامـاً منزايـداً بموضـوع القيـادة وتطـوير أسـاليبها نظـراً للدور الذى تلعبـه فى تحقيق أهداف المجتمع وتقدمـه ورقيه وتتطور القيادة بتطور المجتهـ الذى يعيش فيـه وتززداد مسئولياتها بازديـاد مطالب الحيـاة والتغير السـريع والتطـور الـذى شـمل جميـع مجـالات الحيـاة الاجتماعيـة والاقتـصادية والسياسـية والتربويـة والصـحية من شـأن التأثير على سلوك القادة وتحديد النمط المناسب لكل نشاط في الحياة العامة ، وغالباً ما ينعكس النمط العام السائد في المجتمع على نمط 
القيـادة ، فـالمجتمع الـديمقراطى ينمـو وتزدهـر فيـه القيـادة الديمقراطيـة ، بينمـا في المجتمع الاوتوقراطى تتمو وتزدهر فيه القيادة الاستبدادية. ( · V : V )

وهنـا يجـب الإثـارة إلى أن القيـادة أسـاس النجـاح في جميـع المهن دون إسـتثناء، وفي الحياه أليوميـه، وذلك في ابسط صسورها (الأسـرة الواحدة)إلى أعلى صورها في (قيادة الدولة)، ويظهر ذلك في قول رسول اله صلى اله عليه وسلم: (ألا كلكم راع وكلكم مسئول عن رعيته) ( : : ب (1).

والمعلم هو القائد الثاني في أي مجتمع بعد الوالدين أفالو (Avolio,1999)

وهو الصانع الذي تعهد إليه الأمهة بشرف تتمية شخصية ابنائها تتمية كاملة منزنـة: بقدرته على التأثنير فيهم، وإدراكه لأصسول فنه وبممارسته لتلك الأصـول عن فهم وإيمان برسالته وأهميتها وخطورتها

وتعد العملية التعليمية بما فيها من تحديات العصر تواجه كثيرا من المشكلات

التى أصبحت محور الدراسـة فى مجـال التعليم، وقد تختلف استراتيجيات الأنظمـة التعليمية فى مواجهة تلك المشكلات طبقا لاختلاف الواقع التعليمي فى دول العالم، ولايمكن لأي من هذه الأنظمة التعليمية أن تتغلب على مشكلاتها دون العمل على تجديد ذاتها وإيجاد نظـام عصدري للتعليم يكون جديد فى أهدافه ومحتواه وأسـاليبه ووسـائله بمـا يمكن إخضـاع كافـة العوامـل المؤثرة فـى العمليـة التعليميـة، ومختلف 
القدرات الذاتيـة للمتعلم، وكافة الوسائل المُعينـة على التعليم لصـالح العملية التعليميـة

$$
\text { حتى يؤتى التعليم ثماره المنشود. (ع: مي) }
$$

ويشير إسماعيل محمد (1 . . rم) إلى أن من يقوم بمهنة التدريس لابد أن

يكون على درجة عالية من الكفاءة والاستعداد المهني ،لذلك لزم وجود برنامج تأهيلي يلائم إعداد الطلاب المتعلمين المتزايد لهذه المهنة، مما يتيح فرصة ممارسة التعليم عمليـا على أرض الواقـع بإثـراف المعلم المتعـاون ومشـرف التربيـة العمليـة ومـدير المدرسـة لفترة كافيـة، لتذويـدهم بالمهـارات التدريسية اللازمـة و تمكنهم مـن تطبيـق

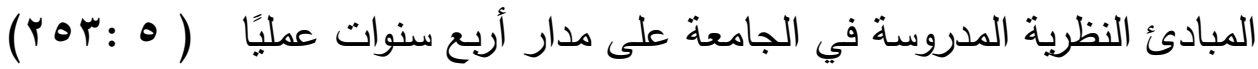
ويتطلب النظام التعليمي الكفء البحث عن هياكل نربوية حديثة وروئية جديدة للمدرسة ودورها التربوي من خلال إدارة قيادية تربوية واعية متعددة الكفايات تتميز بالمرونـة والتكيـف مـع المعطيـات الجديـدة كمـا تتميـز بالقدرة على تحليـل وإدراك

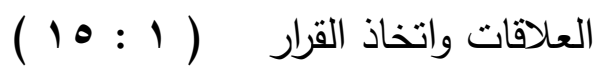

ولقد احتلت القيادة الإستراتيجية مكانة لم بسبق لها وأن حظيت هبا من قبل، وأصبحت تدرّس في جميع الميادين، خاصـةً تلك التي تتعلق بالإدارةعامـة والمؤسسـة خاصة، لكن وبالرغم من ذلك لم تتمكن أغلب المؤسسات من تحقيق تتظيم يتماشى مع إستراتيجيتها المعتمدة لأن المغزى ليس فقط التمكن من طرح الإستراتيجية، لكن 
بـالأحرى يكمـن في كيفيـة وضـعها حيّز التنفيـذ وترجمتهــا علـى أرض الواقـع، فالإستراتيجية لا يمكن تتفيذها إن لم يتم فهها، ولا يمكن فهها إن لم يتم شرحها وتقصيلها، وترجمتها في واقع يكون محلاً للمتابعة.

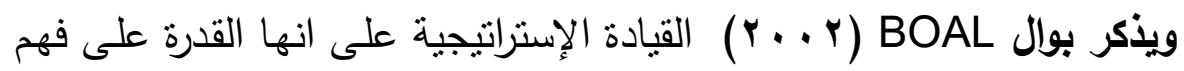

العناصر الرئيسية للتفكير الاستراتيجي المبدع وفهم خطوات عملية التخطيط الخلاق

$$
\text { وتتفيذها فضلاً عن فهم الخطة الاستراتيجية وتدوينها. ( } 17 \text { : } 10 \text { ) }
$$

ومن خلال عمل الباحث كمعلم للتربية الرياضية بإدارة أسوان التعليمية،ومن

خلال قيام الباحث بالعديد من المقابلات الثخصية مـع عدد من موجهي و معلمي التربية الرياضية وجد عدم درايتهم بمفهوم القيادة الإستراتيجية وأهميتها في النهوض بالعمل في مجال التربية الرياضية، وأيماناً من الباحث بأن هنالك حاجة ماسة للتعرف على الأنمـاط القياديـة لدى معلمي ومعلمـات التربيـة الرياضية وضـرورة أن يتصف هؤلاء بصفة القيادة حيث يعد ذلك من المهام الرئيسية في مجال عمهم، وحيث يعد النمط القيادي الذي يمارسه معلم التربية الرياضية وما يترتب عليه من مناخ يسود درس التربيـة الرياضية، أحد العوامل الرئيسـة والمميزة في تحقيق الأهداف التربويـة لدرس التربية الرياضية، مما يساعد في سير العملية التربوية بالثكل المناسب، مما 
دعا الباحث للاهنمام بهذه الدراسة كمحاولة منه لوضع نموذج مقترح لتتمية المهارات القيادية لدى معلمي التربية الرياضية بمحافظة أسوان في ضوء القيادة الإستراتيجية

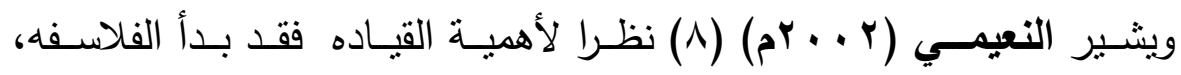
والمفكرين في دراسة الأنماط القيادية منذ أقدم العصور ، ولم بنقطع هذا الإهتمام حتى عصرنا الحالي، فلم تعد تقتصر القيادة على القيادة السياسيه أو العسكريه فحسب، وإنما تعدى ذللك ليشمل القيادة التربوية داخل المدرسة

ويـرى الباحث أنـه بـالرغم مـن اهتمـام الدراسـات الحديثة بموضـوع المهارات القيادية باعتباره أحدث المداخل الرئيسية للإصلاح الإداري في الدول المتقدمة، ألا أن هذا الموضوع لم يلقى الاهتمام الكافي من قبل الدارسين والباحثين في مجال الإدارة الرياضية حتى الآن، وكذلك ندرة الأبحاث على حد علم الباحث التى نتاولت المهارات القيادية لدى معلمى التربية الرياضية في ضوء القيادة الإستيراتيجية في المؤسسـات التربوية بشكلا عام وفى محافظة اسوان بشكل خاص وهذا ما دفع الباحث للسعى الى القيام بهذه الدراسة

\section{أهمية البحث والحاجة إليه :-}

1- التعرف على الوضع الحالي لممارسات القيادة للى معلمي التربية الرياضية ومحاولة الوصول الى أفضل انماط القيادة. 
ץ- الوصول إلى واقع الأداء لاى معلمي التربية الرياضية والتعرف على المهارات القيادية التى يتمتع بها المعلمين - التى

ب- استكثـاف نوع وطبيعـة العلاقة بين ممارسـات القيادة الاسـتراتيجية وتتميـة المهارات القيادية لاى معلمي التربية الرياضية .

ع - قد تساهم نتائج هذه الدراسة في تقديم مجموعة من التوصيات للقيادات الإدارية في مختلف المؤسسـات عـن الواقـع الفعلـي لممارسـات القيـادة الاسـتراتيجية وسـبل تتميـة المهارات القيادية لاى معلمي التربية الرياضية . ه- وضـع اطار معرفي للمعلمين عن أهم النقاط التي قد تسـاهم في الارتقاء وتحسين المهارات القيادية .

צ- فتح افاق جديدة لدراسة مزيد من الموضوعات في ضوء القيادة الاستراتيجية . 


\section{هدف البحث :}

يهدف البحث الى وضـع نموذج مقترح لتنمية المهارات القيادية لدى معلمي

التربية الرباضية بمحافظة أسوان في ضوء القيادة الإستراتيجية .

\section{تساويلات البحث:-}

ا- ما هو الواقع الحالي للمهارات القيادية لدى معلمي التربية الرياضية بالمرحلة الإعدادية

$$
\text { بمحافظة أسوان. }
$$

r- مـا هـو الواقـع الحسالي لممارسـة للقيـادة الإسـتراتيجية لـدى معلمسي التربيـة الرياضـية

$$
\text { بالمرحلة الإعدادية بمحافظة أسوان . }
$$

ب- مـا النموذج المقترح لتتميـة المهارات القياديـة للدى معلمي التربية الرياضية بمحافظـة

$$
\begin{aligned}
& \text { أسوان فى ضوء القيادة الإستراتيجية. } \\
& \text { المصطلحات الواردة في البحث:- } \\
& \text { المهارات القيادية : }
\end{aligned}
$$

يقصد بها الأسلوب الذى يتبعه القائد في تعامله مـع جميع أفراد الجماعة فى

$$
\text { الموقف الذى يواجهه (TV : }
$$




\section{القيادة الإستراتيجية :}

هي القيادة التي تتميز بوضسوح الروئيـة المستقبلية، وتسـى لتحقيق الفاعليـة

والكفاءة في المؤسسة المستتدة إلى العلاقة بين الأهداف والفرص المتاحة وفق مرونة تحقيق حالة من التكامل والتتسيق بين المؤسسـة والبيئة، من خـلا تبني الابتكار والإبـداع للوصـول إلـى تحقيـق الأهـداف علـى المسـتوبين القربـب والبعيـد؛ لوضـع المؤسسة في الصدارة (r ( : ( ) ) الدراسات السابقة : n اولاً: الدراسات العربية: - n

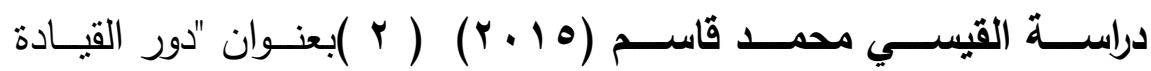
الاستراتيجية في تطوير السياسات الإدارية بوزارة الصحة الفلسطينية " رسالة ماجستير مقدمة الى اكاديمية الإدارة والسياسة للدراسات العليا، غزة، فلسطين. هدفت هذه الدراسة للتعرف على دور القيادة الاستراتيجية في تطوير السياسات الإدارية بوزارة الصحة الفلسطينية. وتكون مجتمع الدراسة من العاملين في الوظائف الإثرافية (مدير دائرة حتى وكيل وزارة )، وقد كان عددهم ( IVT ) موظفاً بقطاع غزة، واعتمدت الدراسـة على المسح الثـامل، وقد بلغت نسبة الاستجابة 97\% حيث تم استرداد عدد ( ITV ) استبيان 
وقـ توصـلت الدراسـة للعديـد مـن النتائج أهمهـا لـن واقع ممارسـات القيـادة

الاستراتيجية بوزارة الصحة بقطاع غزة، (ع ـr7\%) وجود دور القيادة الاستراتيجية في تطوير السياسات العامة حيث كانت درجة الارتباط لبيرسون (0. . • ).

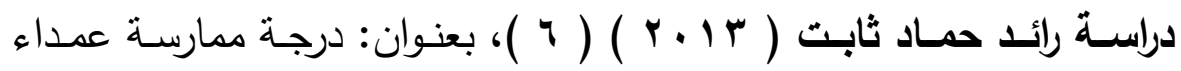
الكليات في الجامعات الفلسطينية للقيادة الإستراتيجية وعلاقتها بتطوير أداء أعضاء الهيئة التدريسية، رسالة ماجستير مقدمة للجامعة الإسـامية،غزة، فلسطين. وقد كان الهـدف مـن الدراسـة التعـرف على درجـة ممارسـة عمـداء الكليـات في الجامعـات الفلسطينية للقيادة الاستراتيجية من وجهة نظر أعضاء الهيئة التدريسية، والتعرف على درجة تقدير أعضاء الهيئة التدريسية في الجامعات الفلسطينية لدرجة ممارسة عمداء الكليات لتطوير أدائهم. وتكون مجتمع الدراسة من جميع أعضاء الهيئة التدريسية في

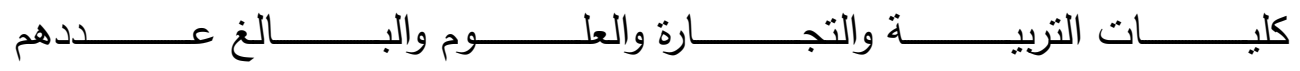
( 470 )عضواً، وتم اختيار عينة عشوائية بسيطة عددها ( ع r ) منهم، أي بنسبة بلغت ( 0 \%) من مجتمع الدراسة. ولتحقيق أهداف الدراسة استخدم الباحث المنهج الوصفي التحليلي، وقد خلصت الدراسة إلى العديد من النتائج أهمها: أن هناى درجة ممارسـة كبيـرة للقيـادة الاسـتراتيجية مـن وجهـة نظر أعضـاء الهيئة التدريسية، كمـا توصلت لوجود تفاوت في ممارسة عمداء الكليات للقيادة الاستراتيجية تعزى (الجنس، 
الجامعة، الكلية، سنوات الخدمة).كما اتضح وجود علاقة ارتباط ذات دلالة إحصائية بين متوسط تقديرات أعضاء الهيئة التدريسية في الجامعات الفلسطينية لدرجة ممارسـة عمداء الكليات للقيادة الاستراتيجية، وبين متوسط تقديراتهم لدرجة ممارستهم لتطوير أدائهم.

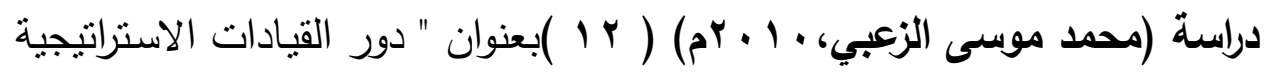
في تظوير المنظمات الأمنية والمدنية في الجمهورية العربية السورية" ،رسالة دكتوراه مقدمة إلى كلية الدراسـات العليا بجامعة نايف العربية الأمنية للعلوم الأمنية وهدفت الدراسـة إلى التعرف على دور القيادات الاستراتيجية في تطوير المنظمـات الأمنيـة والمدنيـة بالجمهوريـة العربيـة السـورية وتوصـلت الدراسـة عدد مـن النتائج أهمها ان للقيادات الاستراتيجية دور في تمكين العاملين وذلك من خلال ايمانهم بالنتيجة التي يعود بها التمكين على المنظمة في خفض الجهد والوقت والكلفة وحذف الاجراءات الزائدة.

ثانيا : الدراسات الأجنبية :

اهتمـت هـذه الدراسـة بالعلاقـة بـين القيـادة دراسـة(Evelyn,2013) الاستراتيجية وأداء الثركات التجارية والمالية في كينيا. تم استخدام الدراسـة الوصفية. وعينة الدراسـة تكونت مـن (^^) اللجـان الدائمـة التجاريـة والماليـة في كينيا. وكان 
المجيبـون أثخخاصـا مسؤولين عن المواردالبشـرية. وقد توصـلت الدراسـة الى وجـود علاقة ارتباط بين ممارسات القيادة الاستراتيجية والأداء التتظيمي، والتي كانت علاقة قوية إيجابية بين التوجه الاستراتيجي للشركات ورضا العملاء.

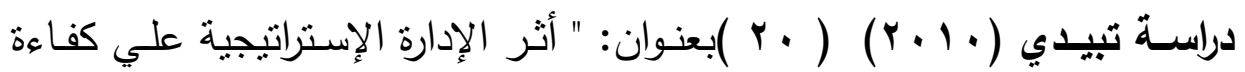

وفعالية الأداء: دراسة قطاع الاتصالات السودانية" رسالة لنيل درجة دكتوراه الفلسفة في إدارة الأعمال، جامعـة النيلين، الخرطوم، السودان. ويهدف هذا البحث للتعرف على مدي تطبيق وممارسـة الإدارة الإستراتيجية في قطاع الاتصـالات السودانية، والوقوف علي اثر تطبيقها علي كفاءة وفعالية أداء هذا القطاع.

دراسة (Fragueiro,2007) (V ) بعنوان "القيادة الاستراتيجية العلمية في مجال الأعمال التجارية والمدارس" هدفت الدراسة إلى القاء الضوء على الترابط بين القيادة الإستراتيجية والعملية الاستراتيجية، فالمدارس التجاريـة تحتاج إلى التركيز توجهات واضحة ومحددة تمكنها من الاستجابة السريعة للسوق من خـل الأعمال والقيادة الاستراتيجية القادرة على النجاح في تحديد الأولويات الرئيسة والاستمرار في تطوير وإيجاد القيمة المضافة. 


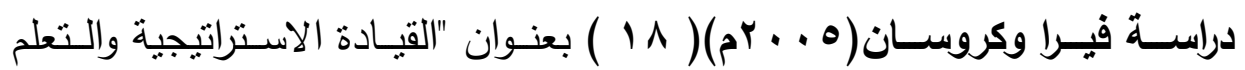

التتظيمي “وهدفت الدراسـة إلى إلقاء نظرة على عمليات التعلم التتظيمي ومستوياته لوصف كيفية نأثير القيادة الاستراتيجية في كل عناصر نظام التعلم وتوصلت الدراسة إلـى نتـائج مـن أهمهـا أن هنـاك فـروق بـين القيـادة الإسـتراتيجية والقيـادة فالقبـادة الإسـتراتيجية ذات حساسية إلى تجـاه الماضـي وحالمـة بالمستقبل وتركز على العمل التتفيذي كنشـاط استراتيجي اما القيادة فهي تتعلق بأي مستوى من مستويات المنظمـة وتركز على العلاقة بين القائد واتباعه.

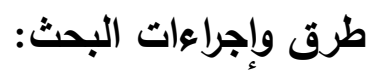

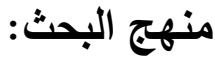

يستخدم الباحث المنهج الوصفي (الدراسـات المسحية) وذلك لملائمته لطبيعـة

$$
\text { وأهداف البحث. }
$$

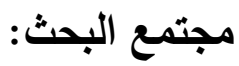

يتمثل مجتمع البحث في موجهي التربية الرياضية بإدارة أسوان التعليمية .

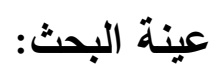

ينتم أختيـار عينـة البحث مـن مجتمـع البحث بالطريقة العثوائية مـن موجهي التربية الرياضية وعددهم (ع • ( ) معلم ومعلمة بإدارة أسوان التعليمية. 


\section{أدوات جمع البيانات:}

يستخدم الباحث التالي لجمع بيانات البحث:

1- تحليل الوثائق والمراجع والدراسات المرتبطة بموضوع البحث.

r- المقابلة الثخصية.

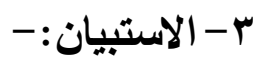

ا ـ استمارة استبيان للتعرف الواقع الحالي للمهارات القياديـة لدى معلمي التربيـة

الرياضية بالمرحلة الإعدادية بمحافظة أسوان •

r. استمارة استبيان للتعرف الواقع الحالي لممارسة للقيادة الإستراتيجية لدى معلمي التربية الرياضية بالمرحلة الإعدادية بمحافظة أسوان .

\section{-الاستنتاجات:}

1 قد يتوافر درجة عالية من المهارات القيادية لدى معلمى التربية الرياضية وخاصة موجهى التربية الرياضية بمحافظة اسوان.

r- قد توجد علاقة ارتباطيه جوهرية بين المهارات القيادية والقيادة الاستراتيجية ، مما يحقق الهدف من المؤسسة التربوية.

r- يستتنج الباحث أنه لكي يتت تتميـة المهارات القياديـة لدى معلمى التربيـة الرياضية بمحافظة اسوان لابد من توفير الدعم المادي والمعنوى لهذه القيادات وتوفير التدريب المستمر للعاملين وأيضاً توفير نظام جيد للحوافز والمكافآت 
لتتجيع العاملين على بذل الجهد والتحسين المستمر للأعمال والخدمات لكي تسنطيع هذه المؤسسات تحقيق الهوف الذي أنشئت من أجله وهو تخريج أجيال من الطلاب قادرين على تحمل المسئولية.

ع - النمـوذج المقترح لتتميـة المهارات القياديـة لـدى معلمي التربيـة الرياضـية بمحافظة أسوان فى ضوء القيادة الإستراتيجية يحقق نتيجة رائعة ومبشرة في ضوء الهدف العام للمؤسسة التربوية.

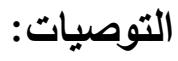

في ضوء أهداف البحث وفى حدود مجتمع وعينة البحث المختارة وفى ضوء الاستتاجات السابق عرضها فإنه يمكن صياغة وعرض التوصيات الآتية: 1- يوصـى الباحـث الإدارة العليـا لمنطقـة اسـوان التعليميـة بمحافظـة اسـوان

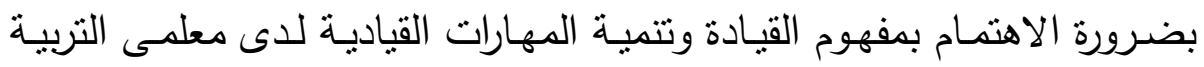
الرياضية حيث بعتقد الباحث بقوة تأثنرهم إلى حد ما على أداء المعلمين في لئهي

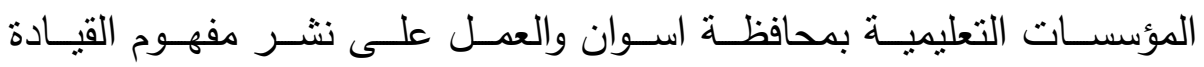
الاستراتيجية في تلك المؤسسات.

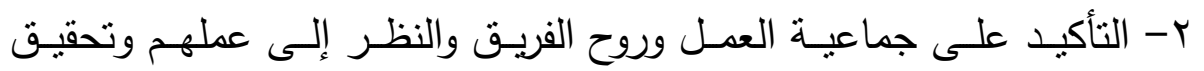

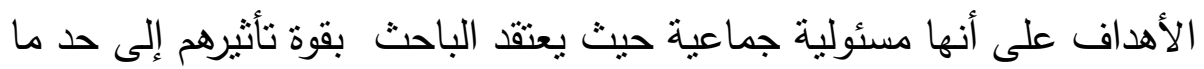

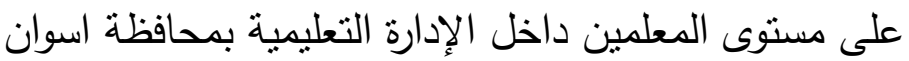
r- ضرورة الاهتمام بتطوير مفهوم القيادة الاستراتيجية في مختلف القطاعات سواء التعليمية او الترفيهية او الاجتماعية وذلك لتحقيق الأهداف و الإنجازات المراد تحقيقها ومستويات الأداء المطلوبة. 


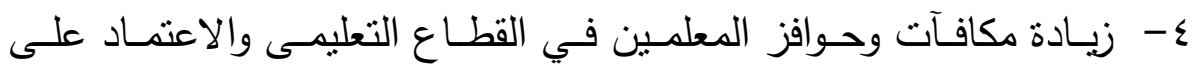
مصـادر دخـل مختلفـة لتطويرالحـوافز وتحسـينها داخـل قطــاع محافظــة اسـوان • التعليمى ه- إتاحـة الفرصـة لدى الأفراد العـاملين للشـور بأهميـة وظيفتهم لمـا لها من علاقه بالاداء وتوصيل الروح الى المعلمين كقادة داخل أماكنهم . ج- ضـرورة التطبيـق النـاجح لمبـادئ القيـادة الناجحـة عن طريـق غـرس الثقـة

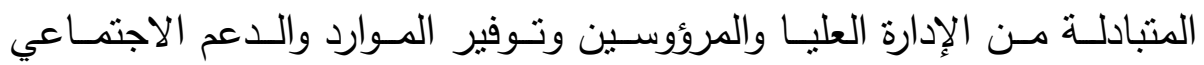

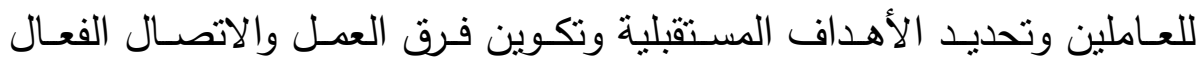
والتدريب المستمر للعاملين. V- محاولة رفع مدركات العـلملين للفوائد والمزايـا من تطبيق نموذج وأسلوب تمكين العاملين وأهميته لتحقيق النجاح فى العمل وذلك لتمية المهارات القيادية لاى معلمى التربية الرياضية بمحافظة أسوان في ضوء القيادة الإستيراتيجية 1- محاولة تطبيق دراسـات مشابهة لهذه الدراسـة على اكثر من صعيد سواء تعليمى او ترفيهى او اجتماعى او تربوي • 


\section{المراجع}

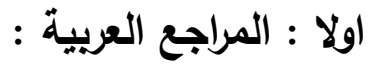

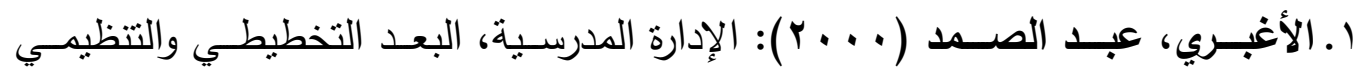
المعاصر • لبنان: دار النهضة العربية للطباعة والنشر

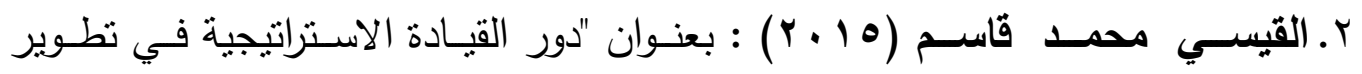
السياسـات الإداريـة بـوزارة الصـحة الفلسـينية " رسـالة ماجسـتير مقدمـة الـى اكاديمية الإدارة والسياسة للاراسات العليا، غزة، فلسطين.

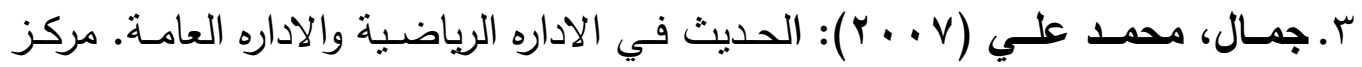

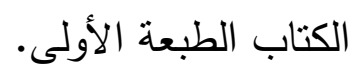

ع. حلـيم المنيـري، عصــام بـدوي (199 1): الإدارة في الميـدان الرياضـي، المكتبـة

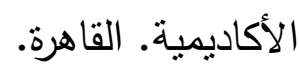

ه. دياب، إسـاعيل محمد(1 + . ץ): الإدارة المدرسية، الإسكندرية، دار الجامعة الجديدة للنشر 


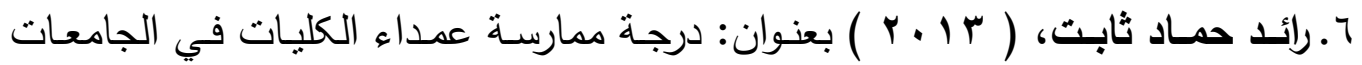
الفلسطينية للقيادة الاستراتيجية وعلاقتها بتطوير أداء أعضاء الهيئة التدريسية، رسالة ماجستير مقدمة للجامعة الإسلامية،غزة، فلسطين

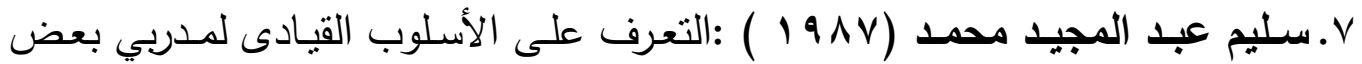
الألعاب الجماعية ، رسالة ماجستير غير منشورة ، كلية التربية الرياضية للبنين

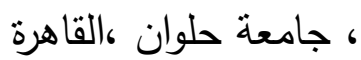

^. سوسن عبد الفتاح احمد (990 99 ) : أثز التفاعل بين أنماط السلوك القيادى والمناخ التتظيمى على الرضـا الوظيفى ، رسـالة دكتوراه غير منشورة ، كليـة التجارة ، جامعة عين شمس ، القاهرة

9. شحاتة، حسن ( 99 ( ) ): النشاط المدرسي "مفهومه، ووظائفه، ومجالات تطبيقه، الدار المصرية اللبنانية، طس، مصر ·

• ا. عباس محمود عوض (1999 ) ) : القيادة والشخصية، دار المعرفة الجامعية ، القاهرة. 


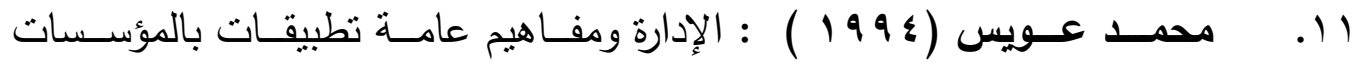
الاجتماعية ، المعهد العالى للخدمة الاجتماعية ، القاهرة

r ا. محمـد موسـى الزعبـي ، • 1 • ب م ) :بعنـوان " دور القيـادات الاسـتراتيجية في تطوير المنظمات الأمنية والمدنية في الجمهورية العربية السورية" ،رسالة دكتوراه مقدمة إلى كلية الدراسات العليا بجامعة نايف العربية

با. مصطفي، أحمد سيد: تحديات العولمة والتخطيط الاستراتيجي: رؤية مدير القرن الحادي والعشرين، الطبعة الثانِية، 1999.

ع ا. مصطفي، أحمد سيد:تحديات العولمة والتخطيط الاستراتيجي: رؤية مدير القرن الحادي والعشرين، الطبعة الثانِية، 1999.

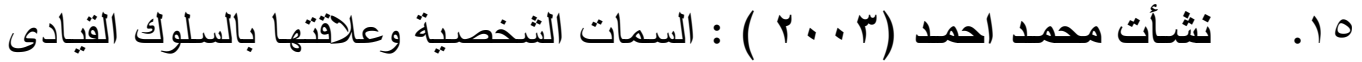
لمـدبى بعض الأنشطة الرياضـية المختـارة ، رسـالة ماجستير ، كليـة التربيـة الرياضية ، جامعة طنطا. 


\section{ثانيا : المراجع الأجنبية:}

16. BOAL, b. K, SCHULTZ, P. storytelling, Tim, and evolution: the role of strategic Leadership in complex adaptive systems. Journal The leadership quarterly, USA, 182002 ,

17. Fragueiro (2007) entitled "Scientific strategic leadership in business and schools"

18. 18. Vera and Krossan (2005) entitled "Strategic Leadership and Organizational Learning."

19. Tabidi (2010) entitled: "The Impact of Strategic Management on Efficiency and Effectiveness of Performance: A Study of the Sudanese Telecommunication Sector" Thesis for a PhD in Business Administration, El-Neelain University, Khartoum, Sudan. 
20. 20. Evelyn (2013) This study is concerned with the relationship between strategic leadership and the performance of commercial and financial companies in Kenya.

21. My presentation (2010) entitled "The Impact of Strategic Management on Efficiency and Effectiveness of Performance: A Study of the Sudanese Telecommunication Sector" Thesis for obtaining a PhD in Business Administration, El-Neelain University, Khartoum, Sudan.

22. (Evelyn, 2013) This study is concerned with the relationship between strategic leadership and the performance of commercial and financial companies in Kenya. 